\title{
Evaluating the Response of Cable-Stayed Bridges Subjected to Delayed Seismic Time-Histories Using Multi-Support Excitation
}

\author{
Bashar Hariri, Lan Lin \\ Concordia University \\ Montreal, Canada \\ bashar.hariri@mail.concordia.ca; lan.lin@concordia.ca
}

\begin{abstract}
Seismic Spatially varying loads for cable-stayed bridges are either neglected or poorly addressed in the most of the current bridge design codes around the world. According to Canadian Highway Bridge Design Code (CHBDC) it is the responsibility of the designer to check the effect of the spatially varying loads while no details are provided. Given this, the objective of this study is to evaluate the effects of multi-support excitation on the response of a cable-stayed bridge. For the purpose of the study, a well-known Quincy Bayview bridge located in Illinois, USA is under examination. The results from the study show that the seismic excitation in the longitudinal direction has caused resonance in the bridge vertical direction, which is due to the delay of the finite shear-wave velocity of the propagation soil at the pier supports. Furthermore, it is observed that the resonance takes place not only in soft soil but also in stiff soil depending on the frequency content of the ground motion, and the modal properties of the bridge. A formula for dominant shearwave velocity for resonance is proposed along with a method to develop the velocity $v s$ response curve.
\end{abstract}

Keywords: Structural Dynamics, Cable-Stayed Bridges, Multi-Support Excitation, Spatially Load Variation, BayView Bridge.

\section{Introduction}

Long-span cable-stayed bridges are very unique structures because of their extreme long spans (longitudinal direction), high pylons (vertical direction), and flexibility (transverse direction). Some of them are located in the seismically active areas, for example, Rainbow Bridge in Tokyo, Japan and Akashi Kaikyō Bridge in Kobe, Japan. Seismic analysis of the cable-stayed bridges is very challenging since the excitation at the pier supports is no uniform due to the delay of the motion in terms of the amplitude and phase between the piers which can be far away as much as $1.1 \mathrm{~km}$ (Russky Bridge, Russia). Give this; the response-spectrum method may not appropriate to carry out seismic analysis. With respect to the time-history analysis, a new spatially load variation approach must be adapted for the following reasons,

1.Difference in arrival time due to finite shear wave velocity (i.e., wave passage effect or phase effect), [1]

2.Loss of coherency of motion due to reflection and refraction in non-homogeneous ground, as well as superposition of waves arriving from extended sources (i.e., incoherence effect), [1]

3.The relative flexibility of the foundation compared to the soil (i.e., foundation effect) [2] such that the foundation and the soil might not vibrate following the same wave.

As described above a distance-altering time-history for each support must be used in the time-history analysis of cablestayed bridges. Accordingly, delayed (not uniform) time histories are considered in this study. It is necessary to mention herein that only wave passage effect/phase effect is considered in deriving the delayed time histories, i.e., the incoherence effect and the foundation effect are ignored for simplicity.

\section{Literature Review}

Research on the spatial variation of ground motions can be dated back forty years ago. In 1975, a simple approach was proposed by Clough and Penzien in 1975 [3] based on three earthquakes. However, the proposed model was criticized because of its simplicity and lacking validation using a large number of records. Furthermore, it is noticed that the results predicted by the model do not well represent the reality. Almost a decade later, a more advanced and detailed methodology was introduced by O'Rourke, Bloom, and Dobry in 1982 [4], which accounts for the direction of propagation. The results from their study were very encouraging, which showed the calculated shear-wave travel times for the 1971 San Francisco 
earthquake were compatible with those using the ground motions recorded by seismographs. However, it is noted that the proposed methods were based on a poor set of ground motion recordings compared to the currently used digitized data. It is known that the seismographs used in the 1980s were positioned mainly to measure the magnitude of the ground motion not the wave propagation. In 1980, the project of the SMART-1 array (Strong Motion Array in Taiwan, Phase I) was launched by the University of California, Berkeley in cooperation with the Institute of Earth Sciences. In total, thirty-seven stations were positioned in a radial way with a central station. The position of the stations was selected for the purpose of building a model for the shear-wave propagation. Since it was launched till 1991, the project has detected and monitored about 60 earthquakes with different magnitudes, focal depths, and epicentral distances, in which the collected data has helped researchers to build models for shear-wave propagation and study spatial correlation factors. One example is made by Loh and Yeh [5] developed a shear-wave propagation model, which takes into account the phase delay due to the limited shearwave velocity and the incoherency effects. They concluded that the spatial variation for a given frequency is governed by the phase delay, which is also recognized as wave passage effect. Harichandran and Vanmarcke, 1986 [6] reported that different frequencies propagate with the same apparent velocity. Zerva [7] studied two cases (Case I and Case II) to evaluate the effects of the spatial loading on the structure. In Case I, a significant loss of coherence of the ground motion was observed when the waves propagated from one support to another. But, no loss of coherence was observed in Case II. The results from both cases were compared with a fully correlated ground motion for all the supports. It is concluded that, "when the motions are both incoherent and differ in phase at the supports of the structure, the response is essentially identical to the one induced by motions that are incoherent (phase difference is zero) for realistic values of apparent propagation velocities"; and "for partially correlated motions that exhibit significant loss of coherence the effect of loss of coherence is more important than the effect of the phase difference, and the latter effect may be neglected" [7]. Regarding the phase delay, Zerva reported that it might produce a higher response than the case of uniform excitation. Recently, some research is focusing on developing a simplified response spectrum method to account for the spatial variation of seismic loads [8] to benefit the practitioners. In addition, Aswathy, Kartha, and Alice, 2013 [9] studied the impact of pounding on bridges due to multi-support excitation considering only the travel wave effect. Their results show that the number of pounding is lower whereas the pounding forces are higher comparing with the case of uniform excitation.

It should be noted that almost all of the previous studies including those mentioned above examined the corresponding displacement in the direction of seismic excitation. However, the study conducted by Allam and Datta [10] revealed that the excitation in the bridge longitudinal direction significantly affected the vibration in the vertical direction. The same observation was confirmed by Yang, Cheung, and $\mathrm{Xu}, 2012$ [11] from shaking table tests. More specifically, Tian and Lou [12] made aware that resonance could happen when the dynamic frequencies of the bridge are close to those of the ground motion time histories, in which the maximum responses are about $40 \%$ larger than those when the uniform excitation is applied. Since only higher modes were included in the analysis and relatively large values of shear-wave velocities were assigned, this $40 \%$ difference was considered to be generated by resonance. Yang, Cheung, and Xu, 2012 [11] also concluded that the maximum effects of the multi-support excitation were about $-25 \%$ to $50 \%$ of those from the uniform excitation as a benchmark.

\section{Bridge Description}

For the purpose of this study, the Quincy Bayview bridge (Fig. 1) in Illinois, USA was considered. This bridge has been used in numerous studies to understand the behaviour of long-span bridges [13], Figure 1 shows the evaluation view of the bridge. It has three spans with $134 \mathrm{~m}+274 \mathrm{~m}+134 \mathrm{~m}$ giving a total length of $542 \mathrm{~m}$ supported with four different cable sections. Figure 2 illustrates the configuration of the superstructure, i.e., a $230 \mathrm{~mm}$ thick, $14 \mathrm{~m}$ wide prestressed concrete slab supported by two steel girders and five stringers with a section of W18x119 spaced at $2.2 \mathrm{~m}$ (centre to centre). Steel beams are used in the transverse direction with spacing of $9.15 \mathrm{~m}$ to support the stringers and to transfer their loads to the main built-up steel girders. There are additional beams in the superstructure to fix the cable mechanism, which are not described in the paper since the detailing is not critical in the structural modelling. The pylons of the bridge are H shaped (Fig. 3) with a height of $71 \mathrm{~m}$ from the water level. The detailed description of the bridge configuration can be found in [14]. 
West $\longrightarrow$ East

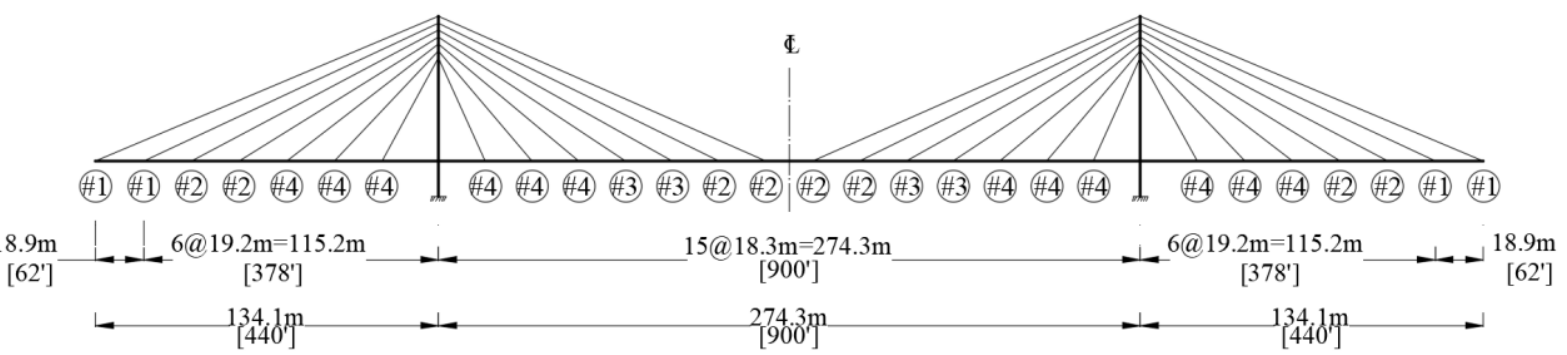

Fig. 1: Bridge elevation view. Source [14].

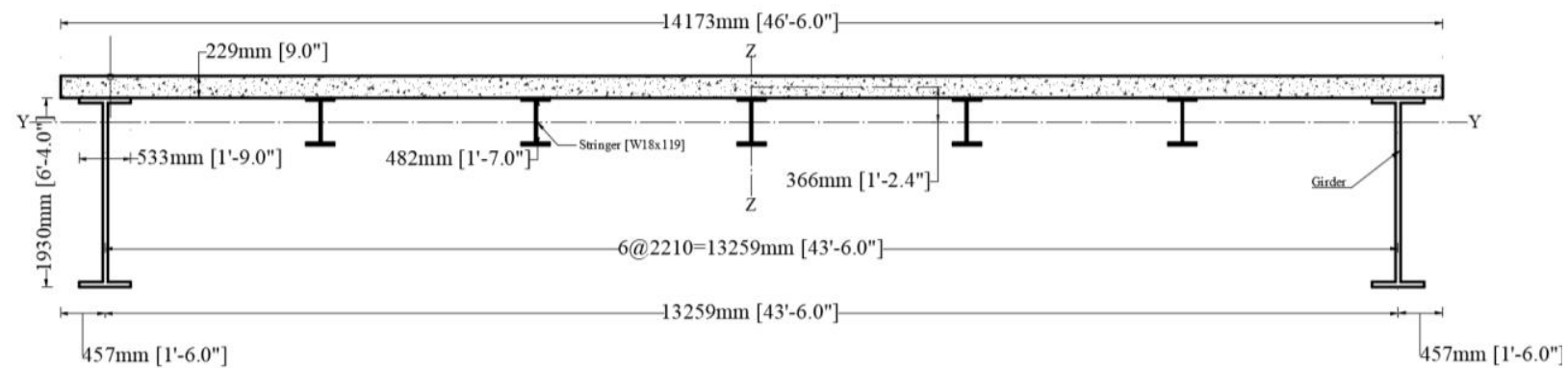

Fig. 2: Bridge deck section. Source [14].

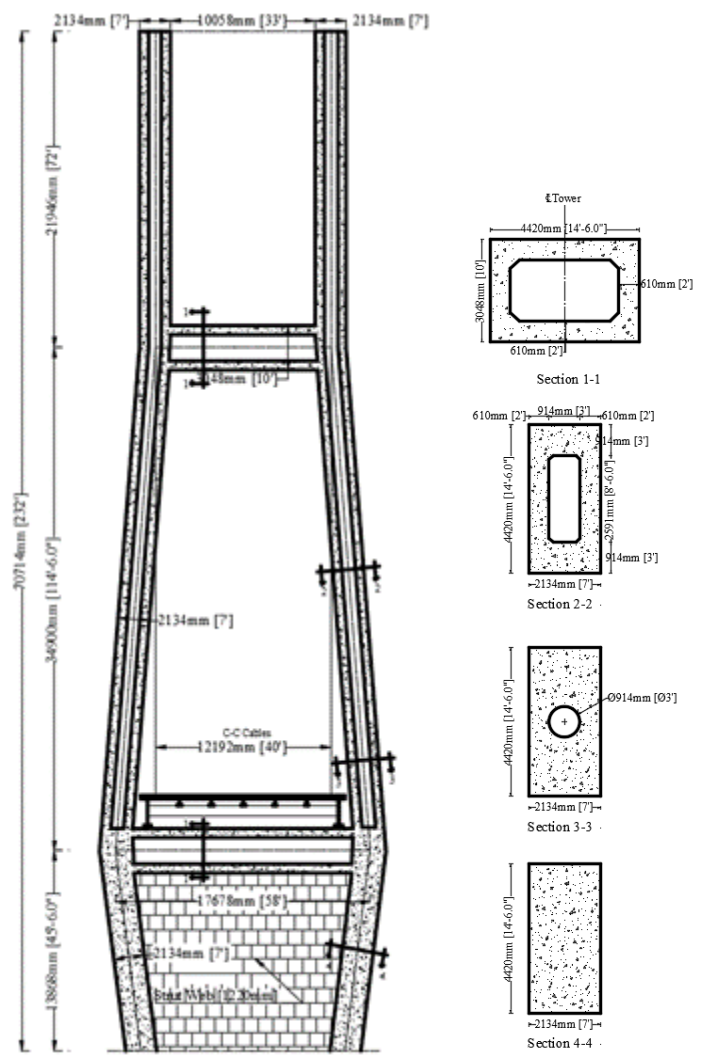

Fig. 3: Section view of the bridge pylon. Source [14]. 
In this study, a three-dimension finite element model of the bridge was developed using SAP2000. Table 1 provides the frequencies of the first ten modes along with the dominant direction of each mode from the study, which is designated as paper model in the table. For the purpose of comparison, the results from the analytical study reported in Wilson and Gravelle (1991) [14], and field tests processed by Wilson and Liu 1991 [15] are also given in the table. It can be seen in the table that the results from the study are very close to those from previous studies.

Figure 4 presents the comparison of the first three mode shapes between this study (i.e., figures on the left) and the previous studies in [14] and [15] (i.e., figures on the right). It is clear that a good match is achieved. It should be noted that comparison was also conducted for other modes, and a similar conclusion was achieved.

Table 1: Modal frequencies of the three models.

\begin{tabular}{|c|c|c|c|c|}
\hline $\begin{array}{c}\text { Mode } \\
\text { number }\end{array}$ & Mode type & $\begin{array}{c}\text { Frequency (Hz) } \\
\text { Paper model }\end{array}$ & $\begin{array}{c}\text { Frequency (Hz) } \\
\text { Wilson model }\end{array}$ & $\begin{array}{c}\text { Frequency (Hz) } \\
\text { Test model }\end{array}$ \\
\hline $\mathbf{1}$ & Vertical & 0.374 & 0.371 & 0.375 \\
\hline $\mathbf{2}$ & Vertical & 0.499 & 0.5 & 0.5 \\
\hline $\mathbf{3}$ & Torsional -Transverse & 0.587 & 0.577 & 0.56 \\
\hline $\mathbf{4}$ & Torsional -Transverse & 0.654 & 0.633 & 0.74 \\
\hline $\mathbf{5}$ & Torsional -Transverse & 0.76 & 0.733 & 0.89 \\
\hline $\mathbf{6}$ & Vertical & 0.833 & 0.77 & 0.8 \\
\hline $\mathbf{7}$ & Torsional -Transverse & 0.966 & 0.949 & 0.11 \\
\hline $\mathbf{8}$ & Vertical & 0.973 & 0.864 & 1.18 \\
\hline $\mathbf{9}$ & Torsional -Transverse & 1.041 & 1.023 & 1.05 \\
\hline $\mathbf{1 0}$ & Vertical & 1.122 & 1.023 & \\
\hline
\end{tabular}

\section{Evaluating the Bridge Responses Under Multi-Support Excitation in Longitudinal Direction}

In this study, the phase delay time $T_{i}$ is determined using Eq.(1)

$$
T_{i}=\frac{l_{s}}{V_{s}}
$$

Where, $T_{i}, V_{s}, l_{s}$ are the delayed time for the excitation at the support number $i$, the shear-wave velocity, and the distance between the support number $i$ and the support number $i-1$, respectively. The analysis was performed first by assuming the bridge foundation is on stiff soil (i.e., site class in accordance with CHBDC [18]) with a shear-wave velocity of $185 \mathrm{~m} / \mathrm{s}$.

It was found that the start time of the excitation at each support from the west direction is $0 \mathrm{~s}, 0.73 \mathrm{~s}, 2.23 \mathrm{~s}, 2.96 \mathrm{~s}$, respectively. Then these delays were used to revise the record from EI Centro earthquake and the corresponding time history was assigned at each support in the model. For illustration, Figure 5 presents the absolute displacement near the middle of the centre span in the vertical and longitudinal directions due to multi-support excitation (MSE) assuming 5\% damping for all modes (analysis method can be found [16], and [17]). For the purpose of comparison, the results from the uniform excitation are superimposed in Fig. 5. 

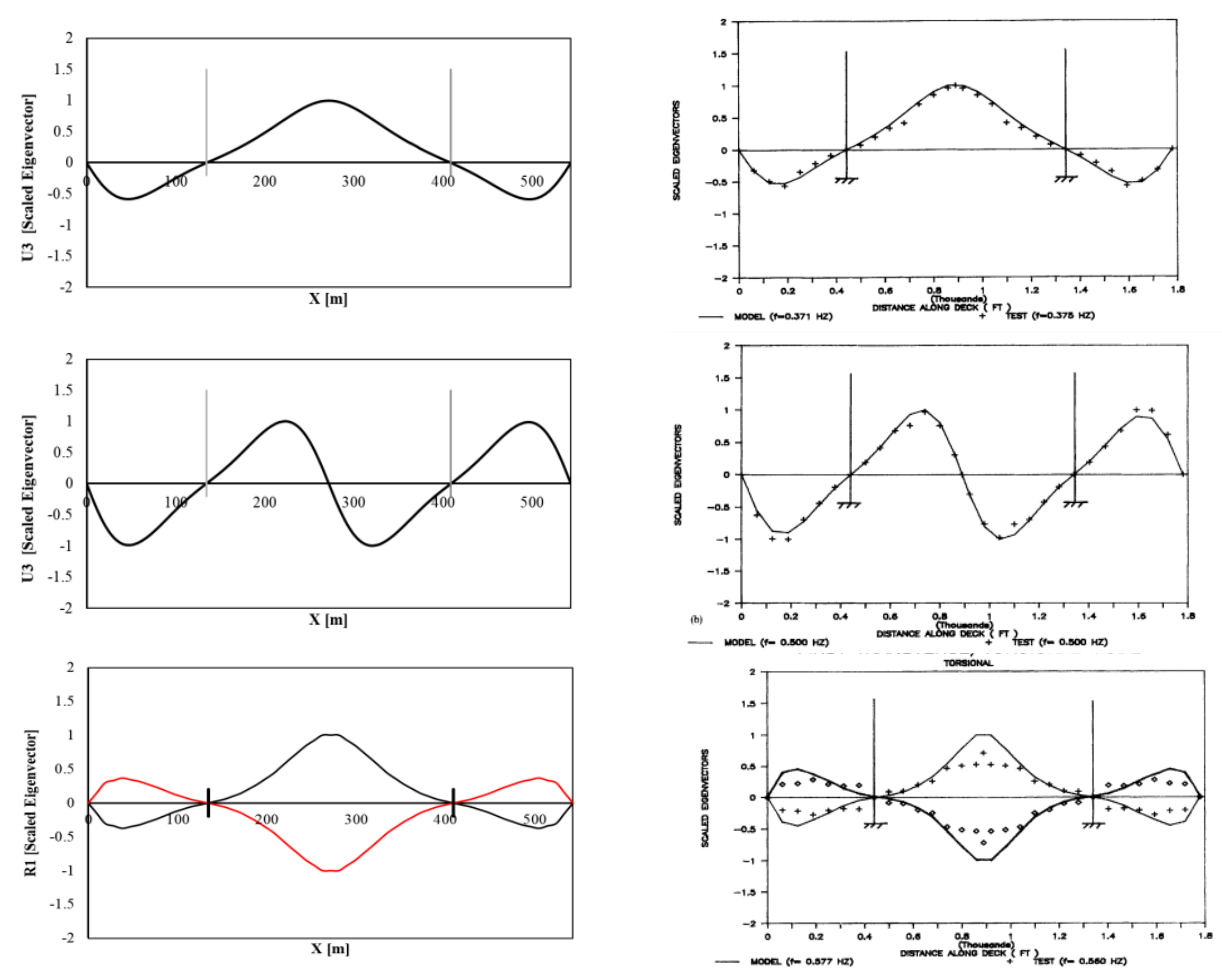

Fig. 4: Comparison of the first three mode shapes.

(a)

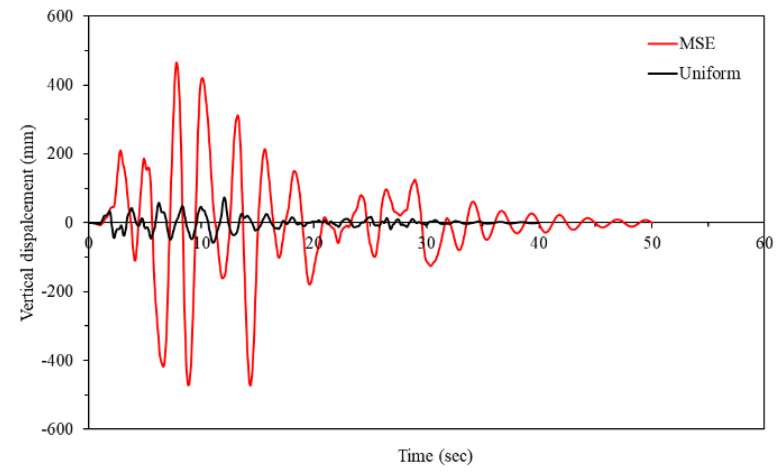

(b)

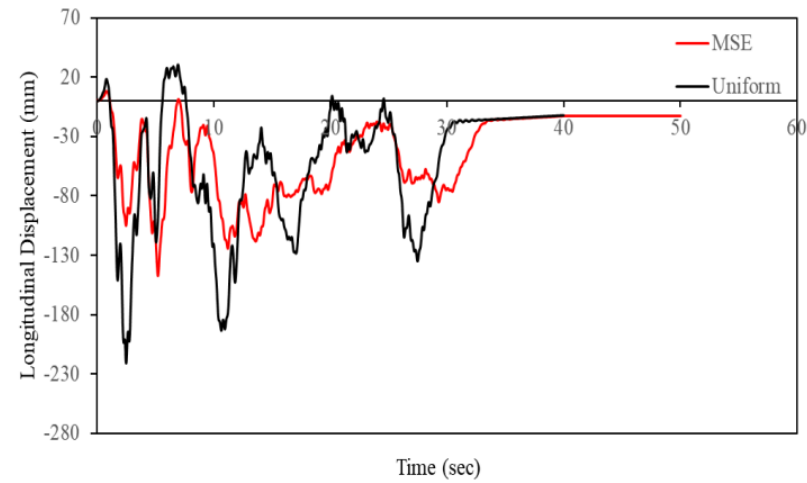

Fig. 5: Results for the absolute displacement near the center of the main span, a: vertical direction; b: longitudinal direction.

As observed in Fig. 5a the vertical displacement due to the delayed multi-support excitation (MSE) is about 6.4 times that from the uniform excitation while the time delay is ignored. However, in the longitudinal direction (Fig. 5b) the displacement when the time delayed is considered is about 0.66 times that the delay is neglected. The results in Fig. $5 \mathrm{~b}$ are not surprising since all the supports are being excited in the same direction and in the same phase. It is very well expected that the displacement in the vertical direction is much smaller than in the longitudinal direction when is excitation is applied in the longitudinal direction. However, it is noticed that the vertical response, when MSE is applied and the time delayed is taken into account, exceeds the longitudinal displacement. This unexpected response is not addressed in the code. More specifically, it is required by the code authority to examine only the responses associated with the direction of the excitation neglecting the potential effects especially in the vertical direction in the long-span bridges if MSE is considered. In the current bridge design codes around the world, the minimum seating width is specified to cover the additional displacements may arise due to MSE. However, the excessive vertical displacement, which may be triggered by the MSE, this phenomenon can be explained by the responses of a simple frame system with one bay and one story with concentrated 2DOFs masses, 
say in $\mathrm{X}$ (horizontal) and Z (vertical) directions, at the middle of its beam under two loading cases. Case I is to apply the uniform sinusoidal excitations at the two frame supports, and Case II is to assign delayed sinusoidal excitations with a time of $T_{i}$ at the supports to represent MSE.

Between these two cases, it is obvious that the vertical ( $Z$ direction) response of the mass will not be triggered in Case I when the uniform excitation is defined in the horizontal $X$ direction since the frame will move as a rigid body in the horizontal direction. While the response in the vertical direction might be introduced in Case II, which can also lead to resonance when the period of the excitation $T_{d}$ equals to the natural period of the vertical mode and when the supports are moving against each other. Eq. (2) represents the proposed equation for calculating the shear-wave velocity of resonance (by means of $T_{i}$ ).

$$
T_{d}=T_{n}=f_{t} T_{i}
$$

Where $T_{i}, f_{t}$ are the phase delay time Eq. (1) using total length of the structure, and phase delay factor, respectively. The phase delay factor determines the amount of phase delay to achieve resonance. For example, it is taken as 2 for the abovementioned frame making the supports moving against each other.

Furthermore, it is questioned that, for the model for the Bayview bridge, the shear-wave velocity of $185 \mathrm{~m} / \mathrm{sec} \mathrm{may}$ not be the velocity of resonance, and the vertical displacement obtained from the analysis of MSE as shown in Fig. 5a may not be the maximum possible response. Therefore, further investigation was conducted to identify the velocity to exercise resonance by developing a visual basic code. Table 2 illustrates the flowchart to perform the examination joined with the output file of SAP2000 in order to develop the velocity vs displacement curve. This investigation was performed using records from El Centro, Loma Prieta, Hollister, Imperial Valley, Northridge, and Friuli earthquakes. The results are presented in Fig. 6. It can be seen in the figure that the maximum response at mid-span occurs when the velocity is about $150 \mathrm{~m} / \mathrm{s}$, which is about $20 \%$ less than the velocity of $185 \mathrm{~m} / \mathrm{s}$ considered in MSE.

Table 2: Flowchart for development of Velocity $v s$ displacement curve.

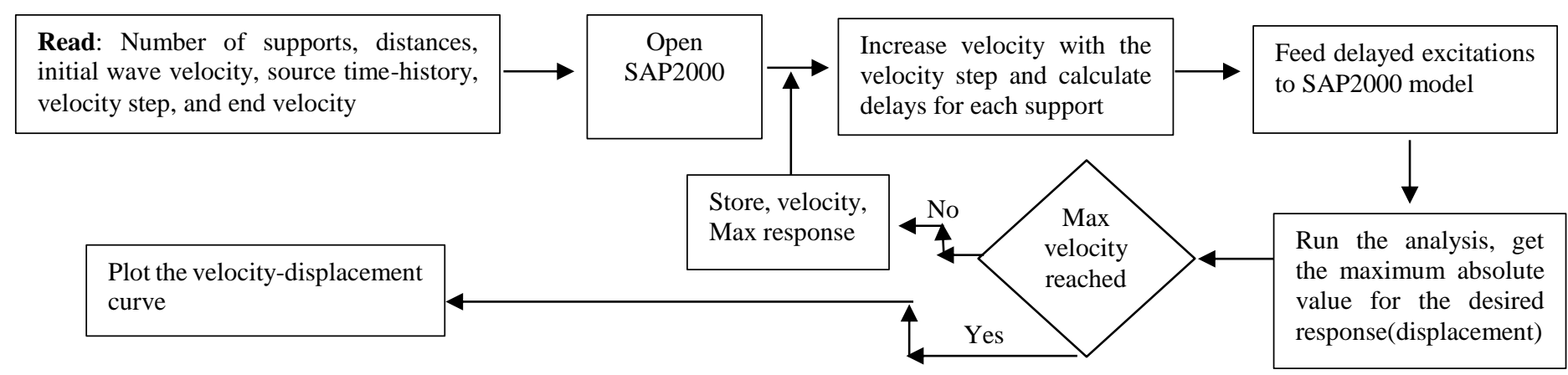

By substituting $T_{n}$ of $0.37^{-1}, T_{i}=$ total bridge length of $542 \mathrm{~m} / \mathrm{shear}$ velocity of $150 \mathrm{~m} / \mathrm{s}$ into Eq. (2), it is found that the phase delay factor $f_{t}$ is about 0.75 . It should be noted that the examination was also conducted using the records from Kobe, Chi Chi, and Kocaeli earthquakes. However, no resonance was observed in these cases. This may be due to the characteristics of the ground motions of these earthquakes as they show a poor frequency content for the range of the dominating vertical mode of the bridge Fig. 7. However, filtering the frequency of the first mode $0.37 \mathrm{~Hz}$ from the Loma Prieta will lead to similar results where the case of resonance was disappeared as shown in Fig. 6. 


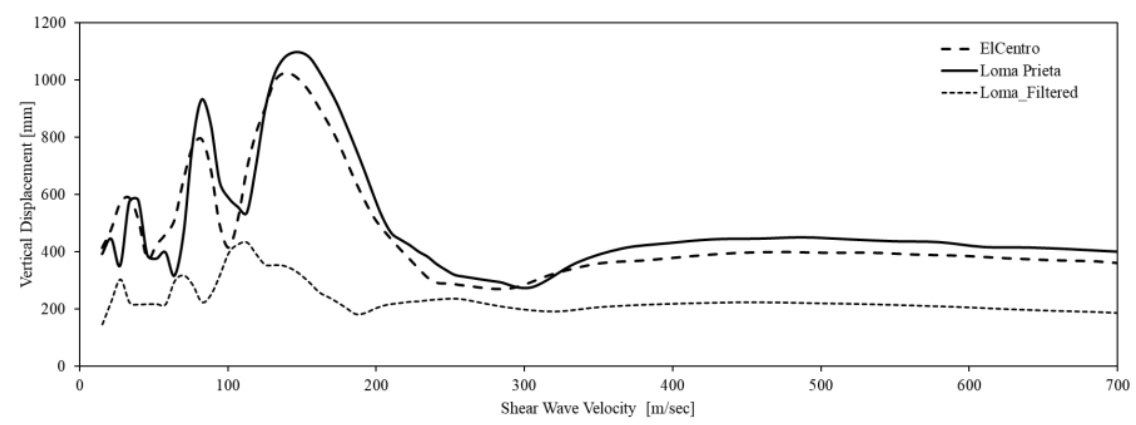

Fig. 6: Results for velocity vs displacement for the model.

(a)

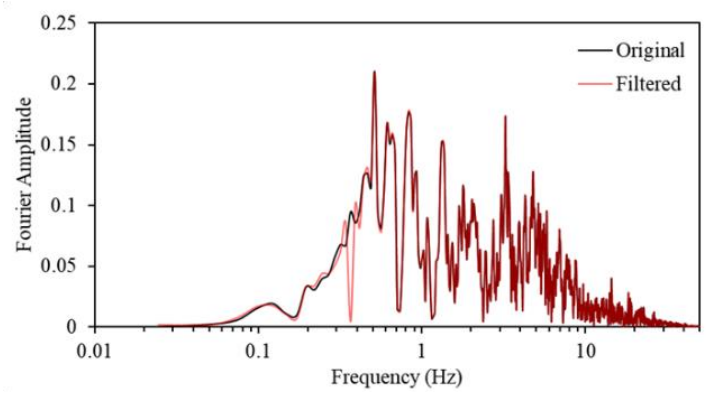

(b)

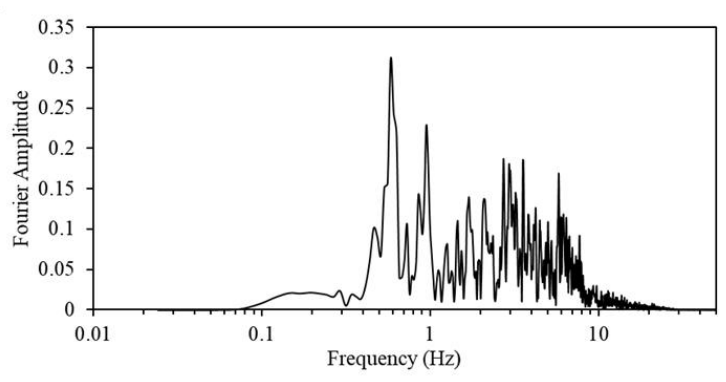

Fig. 7: FFT results. a: Loma Prieta earthquake record; b: Kobe earthquake record

It is also noticed in Eq. (2) that changing the value of natural period of the vertical mode $\left(T_{n}\right)$ will lead to a different dominant shear-wave velocity for resonance. Accordingly, a smaller $T_{n}$ (i.e., stiffer bridge) will shift the resonance velocity to a higher value or vice versa if the phase delay factor $f_{t}$ remains the same. As an example, Figure 8 shows the shifting of the velocity with different $T_{n}$. Table 3 shows recommended values for $f_{t}$ based on the results from the single-story frames using sinusoidal excitation as described above.

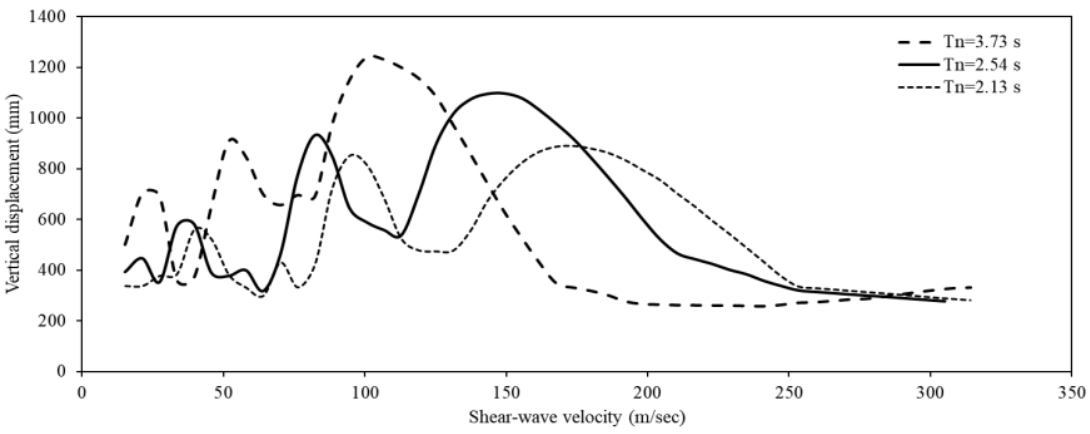

Fig. 8: Velocity vs displacement for different natural period models.

Table 3: Suggested values for $f_{t}$ for symmetrical bridges.

\begin{tabular}{|c|c|c|c|}
\hline Number of supports & Resonance in span & Span length ratio $\left(\boldsymbol{L}_{1 \text { (side span })} / \boldsymbol{L}_{2(\text { main span })}\right)$ & $\boldsymbol{f}_{\boldsymbol{t}}$ \\
\hline $\mathbf{2}$ & - & - & 2 \\
\hline $\mathbf{3}$ & - & 1 & 0.95 \\
\hline \multirow{3}{*}{$\mathbf{4}$} & 1 (Side span) & 1 & 0.9 \\
\cline { 2 - 4 } & \multirow{2}{*}{ 2 (Main span) } & 1 & 0.7 \\
\cline { 2 - 4 } & 1 (Side span) & 0.5 & 0.7 \\
\cline { 2 - 4 } & \multirow{2}{*}{$\mathbf{2}$} & 1 & 0.55 \\
\hline & & 1 & 0.77 \\
\hline
\end{tabular}




\section{Conclusions}

This study evaluated the displacement response of the BayView cable stayed bridge under phase-delayed seismic loading and showed how the vertical response can be affected by the velocity of the shear-wave, natural period, and the frequency content of the seismic excitation.

The main conclusions drawn from this study are summarized as follows,

- Multi-support excitation should be considered in seismic analysis of bridges. This is because it may trigger responses not associated with the direction of loading.

- The wave passage effect cannot be neglected, and the additional displacement might not be accommodated only by the seating width.

- The dominant shear wave velocity for resonance in the vertical direction due to the phase effect can be estimated using the formula proposed in this study by taking into account of the total length of the bridge, span length ratio, and the suggested values of the phase delay factor.

\section{References}

[1] A. Kiuregihan and Neuenhofer, "Response Spectrum Method for Multi-Support Seismic," Earthquake Engineering and Structural Dynamics, vol. 21, 1992.

[2] P. K. a. K. A. Sextos AG, "Inelastic Dynamic Analysis of RC Bridges Accounting For Spatial Variability of Ground Motion, Site Effects and Soil-Structure Interaction Phenomena Part 1: Methodology and Analytical Tools," Earthquake Engineering and Structural Dynamics, 2003.

[3] R. W. Clough and J. Penzien, Dynamics of structures. New York: McGraw-Hill, 1975.

[4] M. J. O'Rourke, M. C. Bloom and R. Dobry, "Apparent propagation of body waves," Earthquake Engineering \& Structural Dynamics, vol. 10, pp. 283-294, 1982.

[5] C.-H. Loh and Y.-T. Yeh, "Spatial variation and stochastic modelling of seismic differential ground motion," Earthquake Engineering \& Structural Dynamics, vol. 16, pp. 583-596, 1988.

[6] R. S. Harichandran and E. H. Vanmarcke, "Stochastic vartion of earthquake ground motion in space and time," ASCE, vol. 114, pp. 154-174, 1986.

[7] A. Zerva, "Effect of spatial variability and propagation of seismic ground motions on the response of multiply supported structures," Elsevier Science Publishers Ltd., Philadelphia PA19104, USA, 1991.

[8] L. Jianhua and L. Jie, "An Efficient Response Spectrum Analysis of Structures Under Multi-Support Seismic Excitations," in 13th World Conference on Earthquake Engineering, Vancouver, B.C., Canada, 2004.

[9] S. Aswathy, G. Unni Kartha and M. Alice, "Seismic Pounding of Bridges due to Multi-Support Excitation with traveling wave," American Journal of Engineering Research (AJER), vol. 4, pp. 29-32, 2013.

[10] S. M. Allam and T. Datta, "Seismic Response of Suspension Bridges Under Multi-Component Non-Stationary Random Ground Motion," JSEE, vol. 5, 2003.

[11] C.-Y. Yang, M. M. Cheung and X. Xu, "Wave Propagation Effect on Seismic Response of Cable-stayed Bridge: A Multiple Shake Tables Test," in World Conference on Earthquake Engineering, Lisbon, Portugal, 2012.

[12] Z.-Y. Tian and M.-1. Lou, "Traveling Wave Resonance and Simplified Analysis Method for Long-Span Symmetrical Cable-Stayed Bridges under Seismic Traveling Wave Excitation," Article ID 602825, 12 pages, 2014.

[13] C.-H. Hua and Y.-C. Wang, "Three-Dimensional Modelling of a Cable-Stayed Bridge for Dynamic Analysis," Taiwan, 1995.

[14] J. C. Wilson And W. Gravelle, "Modelling of a Cable-Stayed Bridge for Dynamic Analysis," Earthquake Engineering And Structural Dynamics, vol. 20, pp. 707-721, 1991.

[15] J. Wilson And T. Liu, "Ambient Vibration Measurements On A Cable-Stayed Bridge," Earthquake Engineering and Structural Dynamics, vol. 20, pp. 723-747, 1991.

[16] A. K. Chopra, Dynamics Of Structures Theory and Applications to Earthquake Engineering, 4th ed. Berkeley, CA: Pearson, 2011.

[17] R. Jangid, Introduction to Earthquake Engineering. Bombay: NPTEL, 2013.

[18] C. CHBDC, Canadian Highway Bridge Design Code, S6-2014. 